\title{
The Contents of Students' Independent Education and Methods of Implementation
}

\author{
Hayitova Shakhnoza Daniyarovna ${ }^{1}$, Kulmuradov Dilshod Istamovich ${ }^{2}$, Umirov Ilhom \\ Iskandarovich $^{3}$ \\ ${ }^{1}$ An Independent Researcher of the Department of "Vocational Education"of the Jizzakh Polytechnic Institute, \\ Uzbekistan \\ ${ }^{2}$ a senior teacher of the Department "Ground transportation systems" Jizzakh Polytechnic Institute, Jizzakh, \\ Uzbekistan \\ ${ }^{3}$ An assistant of the Department of "Vehicle Engineering" at Jizzakh Polytechnic Institute, Uzbekistan
}

\begin{abstract}
This article outlines the content, ways of organizing students' independent learning, the types and objectives of independent learning. It also reveals the levels and criteria of independent learning activities, the stages of implementation of independent learning, the ways of developing skills and competence of working independently, as well as the degrees of independent learning.
\end{abstract}

Key words: education, creative, degree, criteria, knowledge, skills, competence, independent education, independent work, degrees of education.

Article Received: 16th October, 2020; Article Revised: 30th December, 2020; Article Accepted: 08th January, 2021

\section{Introduction}

Undoubtedly, the changes in the education system of our country, new laws and decrees will positively affect the development of our society. They are an important factor in enhancing the country's intellectual potential, training mature, competitive personnel that meet the state educational standards.

In the first stage of the higher education system, the educational programs envisage mastering of the subject blocks (humanities, socio-economic, mathematical and natural sciences, general professional and supplementary) in the curriculum, while ensuring continuity and continuity with general secondary and secondary special and vocational education. At present, attention is insufficient to be paid to the organization of independent education and ensuring its effectiveness in the preparation of undergraduate teachers in vocational colleges. The problem is the failure of prospective undergraduate teachers to pursue professional development in their free time, the lack of necessary literature for independent learning in libraries, and the ineffective use of information technology. To solve this problem, it is necessary to systematize students' independent learning.

Independent education is an important factor in becoming a competent professional. This is especially true in the system of vocational training. Our ancestors also paid attention to the education of the younger generation as a professionally mature, nurturing and progressive person.

\section{Literature Review}

Positive features of independent work and independent learning from scholars: V.I Andriyanova's teaching to work independently in russian classes in the 5th and 6th grades of Uzbek schools [1], Sh.Sharipov's Pedagogical Fundamentals of Student Creativity [14], Sh.Yunusova's formation of students' educational activity [15], Q.P.Husanbayeva's teaching students to think independently in the process of literary education. These scholars researched such problems scientifically [11] Z.Nishonova, J.Tolipova, I.Ackarov, N.Halilov's 
research about forms of independent education has been viewed $[8,9,10,2,3$, 13].

The research work of the teacher S.Matjonov is devoted to the organization of independent work of students, where the issues of oral and written creative work of students are studied. After all, creative work and independent work in the formation of a spiritually mature generation requires free thinking. A student who does not have an independent mind can not think independently [5].

The majority of pedagogical scholars consider the issue of activation of the process of organizing independent learning as a common problem. In particular, a part of the work in this regard is the individual approach to organize students' independent learning. At the same time, independent education is considered to be an important factor in the formation of an active, educated, and socially responsible person in pursuit of high results in education and professional development.

\section{Research Methodology}

In order to organize an independent education, you need not only an interest in a particular profession or area of activity, but also the ability to do that. Given that self-education is governed by the individual, the individual can freely choose the resources and use the goals, the means, the content at any time.

Autonomy in independent learning is the ability to identify and select objectives, principles, content, methods and means of learning, without the hassle and need of external influence.

Since independent learning is directly linked to independent thinking, it is also desirable to express it as : "Independent thinking is the use of one's intellectual abilities in a variety of ways, methods and means, based on their own knowledge and life experience, setting goals and objectives for the problems they face. It is a mental activity that is self-solving at the level of competence " [11].

The ability to work independently in young people can be used to teach a variety of educational subjects. For example, mathematical scientists S.Demidova and L.O Denisheva described independent learning as follows:

"The content of the work of the students by the teacher is understood as the time that is devoted to the organization of independent work, the implementation of the didactic objectives assigned to them. The process of summarizing and systematizing knowledge in the search for, understanding, consolidation, and the formation and development of skills is understood.

This definition refers to the characteristics of activity: activity, systematicity, purposefulness, and independence. But as an aspect of independent learning, independence is mentioned. Independent thinking can be part of education.

The interest and ability to acquire independent learning in future undergraduate teachers should be shaped as a prerequisite for improving the pedagogical culture. Future undergraduate teachers in the field of vocational education will be required as an important factor in solving this problem.

The power of motivating students to learn independently, depending on their motivation, is the meaning of independent learning. They set goals and objectives. This can be summarized as follows:

1. Political independent education, modern realities and attitudes that are important for independent activities;

2. Independent professional education during the preparation period, aimed at the development of independent learning of students to work in their chosen field of study;

3. Independent learning, based on personal and life plans, personal interests, and deeper learning.

4. Independent education related to the development of talent and hobbies.

5. Independent education aimed at 
developing the character.

Professional self-education is a key factor in the development of an individual, which characterizes the ability to work independently in their future activities. The content of independent education depends not on the nature of work, but directly on the ability to find opportunities for independent education. Independent learning is a tool for a student to determine his or her own path to future activity and to help students evaluate their own abilities. Although the student does not feel a clear need, there is a neurological need for self-satisfaction, self-expression, self-existence.

In order to achieve this goal, the teacher of vocational education should aim to achieve a specific goal of selfimprovement.

1. The content of self-education should be suitable to the specific conditions of the educational institution, the practice of the educational institution where the teacher training is conducted.

2. The teacher of vocational education shall have the following qualities, on a specific purpose and in accordance with the procedure:

- deepening of students' aspirations, interests, understanding, taking into account their spiritual needs;

- emotional communication with students, actively influencing their intellectual, ethical and practical activities.

3. The teacher of vocational education must study independently the list of questions on general pedagogy, psychology, occupational hygiene and physiology, techniques and technology.

4. The teacher of vocational training should choose the most effective methods, ways of working out system of work on improvement of pedagogical skills, correctly select technological process and technical objects.

5. It is desirable for the teacher of vocational training to use their own forms of self-improvement and practical exercises, taking into account the specific conditions and the individual conditions.

6 . The teacher of vocational education should organize and improve their knowledge in the form of continuous creative research.

To do this, he must:

- have tendency to lead the process of creative research;

- remember the effectiveness of creative research depends on the pedagogical, psychological and theoretical training of the teacher.

"Independent education" means the organization of a subjective, systematic, independent and autonomous activity of the learning process to develop the concepts, skills and abilities of knowledge acquisition [6].

As a result of the research it was found that the attention was insufficient to be paid to the problem of organizing independent learning of students of pedagogical institutions. There is insufficient scientific justification for the forms, methods, and tools used in the independent education of teachers in vocational training. First of all, it is proved that a student has sufficient motivation, desire and ability to work independently in order to be fully engaged in independent learning. In addition, a number of psychological factors are also influenced by students' independent learning. The psychological impact of independent learning is discussed in the next chapter of the thesis.

The above mentioned points show that the independent education of a teacher of vocational education is important in training new creative thinking personnel.

The concept of "independent learning" is defined in pedagogical dictionaries as a form of learning that is gained by learning outside the school. Currently, the terms "independent learning", "self-education", "independent learning" are used interchangeably.

Based on the results of scientific research, independent learning is defined as: independent learning - a systematic 
activity aimed at developing theoretical knowledge, practical skills and abilities by independent study material, creative and independent execution of practical tasks both in the classroom and outside the classroom. Independent work varies depending on the didactic purpose, function, degrees of complexity, for whom (for individual or collective). In the course of independent learning, it is important that the chosen topics are scientific, systematic, and the content of the teaching materials, practical, interdisciplinary, and the creative nature of the assignments and assignments given. Analyzing its theoretical, practical, scientific, methodological and pedagogical bases, it is possible to achieve positive results if selected effective forms and tools. The importance of the topic, practicality, scientific and educational content, the systematic nature of the topic, the versatility of the tasks play an important role. But most importantly, it is important to pay attention to the aspirations and interests of students in organizing their own learning activities. It is important to ensure that students are able to apply the acquired knowledge in practice, to participate in socially useful and outreach activities.

Observing the educational activities of students studying in the field of vocational education, it was found that conscious interest is the driving force behind independent activities.

It is precisely the conscious interest in the professional disciplines that motivates students to practice self-actualization, reflection and broader comprehension in practice. Motivational environments of students in the field of vocational education are shaped by other sources and their interest in the profession. Conscious interest is the most important degree of the independent activity. This depends on the level of skill of the teachers in the subject and the students' interest in a particular subject or profession. Although there is no time for students to be aware of all the secrets of the profession, the information provided by the teacher is important in taking the first step in their interest.

It is time-consuming to explore ways to develop students' methodological guidance in independent learning. The most sustainable way of motivation is professional work and creative approach to work. Involvement of young people in various practical, social, organizational and creative activities is also a factor in increasing the effectiveness of independent learning.

How independent learning is carried out, its development, and the levels of independent learning can be determined by the following criteria:

- independent learning in a purposeful, motivational environment;

- skills that enable the process of independent thinking;

- skills aimed at organizing independent learning activities.

In the process of independent learning, students refer to additional literature, review the topics covered. Many students work on home-made lecture texts, use popular scientific publications, periodicals for lectures and essays.

While carrying out independent pedagogical and technical-technological work, the student acquires methods of solving the problems of future professional activity. Performing independent pedagogical and technicaltechnological work is considered as a means of management, encouragement, organization and control, which increases the level of independent learning in didactics [2, 3].

Specific requirements for the student's learning activities by the teacher enrich their content. The form of assignment of tasks for pedagogical and technicaltechnological independent work is the accomplishment of management tasks and tasks, which involve drawing conclusions on the previously acquired sample.

In our view, there is great potential for 
independent teaching and learning in the field of pedagogical and technical and technological work. It can serve as the basis for the creation of a set of tasks that allow the independent learning of pedagogical and technical-technological work.

It reflects objective, concrete pedagogical and production problems in independent pedagogical and technical-technological work. When a teacher uses a problematic situation to reflect the contradictory nature of the pedagogical phenomena studied and the production process, the objective problem becomes a learning problem. Problems of educational pedagogical and production process, which are understandable to students, are considered as educational tasks.

Problems of the learning task allow for the activation of thinking activity, but each does not lead to the independent formation of pedagogical and psychological concepts at the scientific level. Therefore, the development of independent pedagogical and technicaltechnological work should take into account the didactic nature of the learning problem. If the task is presented correctly, it will be easier for the student to accept them.

The rules for the development of independent pedagogical and technicaltechnological work in accordance with the theory of independent learning include:

- independent pedagogical and technicaltechnological work should have problems with actual pedagogical and production conditions;

- implementation of various methods of problem solving (analysis, synthesis, comparison, summarization, etc.), which form the basis of independent work;

- should be able to identify evidence of independent work and generate ideas based on a strong link between students' experiences, events and processes;

- a more or less coherent expression of the performance of problematic tasks may result in a more complex understanding of the subject that has not yet been mastered by a few simple concepts that constitute the terms of the task;

- simple concepts or concepts that are not known to the subject are compared to each other in the performance of problematic tasks;

- when comparing concepts, the subject performs various types of thinking: analysis, synthesis, comparison, comparison, finding commonality, specificity and specificity between technical objects;

- in carrying out tasks with problem situations the subject performs the following:

- reproduces concepts without changing the form and content of concepts;

- changing the form of concepts and reproducing them;

- reconsider previously acquired concepts using formal-logical reasoning;

- formulates new concepts based on theoretical thinking [7].

Independent pedagogical and technicaltechnological work is often presented to students in the form of an immediate problem. The content of independent pedagogical and technical-technological work often reflects the problems encountered in practical life. Students need to redescribe them so that they can draw on existing experiences and distinguish the conditions that allow them to reach a solution.

If the student does not find a solution in the process of teaching tasks that have been turned into a problem by the teacher, he or she will not be able to find a specific situation that will allow them to seek a solution to the pedagogical and production process problem. Solving the problem requires adherence to certain didactic tasks. The student is not required to demonstrate the ability to change the situation when the conditions of the matter are already determined by the developer. Students therefore have difficulty transferring their knowledge and applying them to practice. 
In independent learning, you often have to perform tasks that are not always clear. As the student solves the problem, he / she is familiar with the procedure for changing conditions, analyzes a specific problem and uses existing skills and abilities to perform a teaching or pedagogical or technical-technological task.

Such pedagogical and technicaltechnological work can be classified into the following types:

1. Issues where the conditions are stated but not all the information necessary to solve them. They are divided into two groups: theoretical and practical. Practical issues are inextricably linked to actual pedagogical and production processes. Addressing such issues requires not only mental activity, knowledge, skills, but also sensory and motor activity. These issues will help to ensure the continuity of independent learning technologies.

2. Issues that cannot be mastered without mastering knowledge, action and operations. These issues are designed to consolidate previously acquired knowledge, apply them in new situations, acquire critical thinking skills and strengthen existing knowledge.

3. Questions are a means of identifying readiness to learn and assimilate new knowledge. The questions highlight two aspects: validating existing knowledge and directing it to independent conclusions. The questions are divided into two groups: reproductive and productive. Reproductive questions promote memory, and productive questions help to develop thinking skills. They help the subjects to master the mental behavior, as well as develop the skills of analysis, synthesis, comparison, summarization, separation of importance, independent decision-making and practical decision-making.

Students identify different features and interactions between pedagogical phenomena, technical objects, technological processes (analyze and summarize actions), compare, compare them with the generality of the phenomenon, processes and objects, with the help of independent pedagogical and technical-technological work. Training tasks are progressively complicated. Talented students with the best preparation perform complex and creative tasks. Less well-prepared students perform more simple tasks, but working on assignments allows them to work together as a team to solve a common problem. Performing complex tasks gives some students an instant understanding of the pedagogical, psychological and technical-technological concepts [7].

These students are characterized by activity, development, purposefulness of independent activities, systematic work, interest in learning and independent work, the desire to deepen their knowledge on the basis of advanced methodological guidelines. Students often only remember and tell the teacher, without understanding the material in the textbook. Such students are accustomed to working solely on a task basis in their professional activities. They act only on the "Sample" given. As a result, they do not seek to have active independent thinking. This is expressed in the following conclusions: The teacher explains to them complex material and the student works on the material, but does not work on more complex material. The teacher explains in a simpler, more understandable language for students to work independently than is written in the book.

The main source of interest in the first phase of independent learning is science. However, this interest is not sufficiently solid and profound. However, there is no purpose-oriented, systematic, specialized organizational, independent educational activity. Only reading books, listening to special lectures, and striving for independent thinking activity. The individual has no interest in independent learning activities, and he does a lot of 
extra, large-scale work, but does not do it on a regular basis, and sometimes without deep knowledge.

In the second phase of independent learning, students independently (of course) set goals and objectives, understand the meaning of independent activities and carry out organizational work. During this period, students solve professional tasks as a means of implementing personal - life plans and ideas. In the second phase, their interest in independent work becomes more serious, with a strong desire to learn a particular subject, to make their own life plans, to pursue a profession. It is consciously engaged in extracurricular activities, and there appears a desire for self-education, which has become a means of implementing its ideas. Consistently organize independent learning.

In the third phase of independent learning, students will be engaged in independent learning for a number of years and will have the ability to clearly define their career goals and objectives.

Assessment of the level of independent learning is compared with self-assessment and teacher evaluation.

Teachers play an important role in preparing students for independent work. The teacher should identify the topic of the independent work in accordance with the student's ability and knowledge to motivate them. It is necessary to provide all the information necessary for this work with methodical instructions and to organize questions and answers, consultations and excursions on these topics when needed.

Currently, independent work done outside the classroom can be done in the following ways:

- preparation for lectures, workshops, seminars and laboratories;

- independent study of topics in the curriculum subjects that are not learned during lectures;

- searching for information on the Internet;
- preparation of coursework, course projects, final qualifying works and master's theses;

- search of literature independently through the catalog of the Information Resource Center;

- listening to audio recordings, viewing video materials;

- study of textbooks, manuals on the studied subject;

- exercise control;

- writing reports, abstracts and essays on topics;

- preparing reports at seminars and conferences;

- solve problems and examples from practical exercises;

- creating albums, schedules, schemes, rebuses, tests and crosswords for systematic study of learning materials;

- develop visual aids for individual students or groups of students on the topics under study;

- summarize independently researched questions;

- solving tests to consolidate the knowledge gained in the lecture;

- creative and scientific work;

- participation of students in scientific societies and circles;

- participation in competitions and contests;

- preparation of reports on past practice, scientific reports to student conferences;

- perform calculations and graphic works;

- preparing for current, intermediate and final controls;

- interpretation of monographs [12].

The following four types of independent work are mentioned in the scientific and pedagogical literature: independent work on samples, reconstructive-varieties, heuristic (partially creative), independent research. However, they do not refer to the results of the above independent studies, to analyze, analyze, synthesize, evaluate, and draw conclusions. In our view, the analysis and synthesis of independent creative research results are also of great pedagogical significance 
(Figure 1). In addition to compiling the content, it was found that students' selfexamination and control of their work would have a positive effect on developing the skills and abilities of independent work. Their essence is described as follows:

- in the independent work of samples, typical tasks are performed, that is, various exercises, practical tasks are performed on the basis of samples. Independent work on samples contributes to the mastering of learning materials, but does not stimulate students' creative activity;

- reconstructive and varieties independent work not only reproduces the practical description of knowledge, but also the content of knowledge

requires their practical use in solving a problem or problem;

- problems raised in lectures, labs, workshops, seminars in heuristic (partially creative) independent works;

- in creative research the student independently seeks out and researches ways to solve the problem. Such tasks include piloting, designing equipment, models and tools. Independent research in the form of creative research gives students the ability to see the problem, and as a result, they can independently express the problem and develop a plan for their solution.

\section{Figure 1.1. Types of Independent work}

In the process of research, we have also summarized the results of independent research in the nature of creative research based on the analysis and synthesis of independent research.

By analyzing and synthesizing the results of creative research, the student learns the independent work.

\section{Analysis and results}

The curriculum included in the teacher training curriculum provides students with independent knowledge on a number of issues and issues related to the subject.

$\begin{array}{lll}\text { elements of } \mathrm{kn} & \text { The types of independent work } & \text { chelor and } \\ \text { acquired thr set at } 54\end{array}$ determine how well they achieve their hours per week. Of these, the amount of

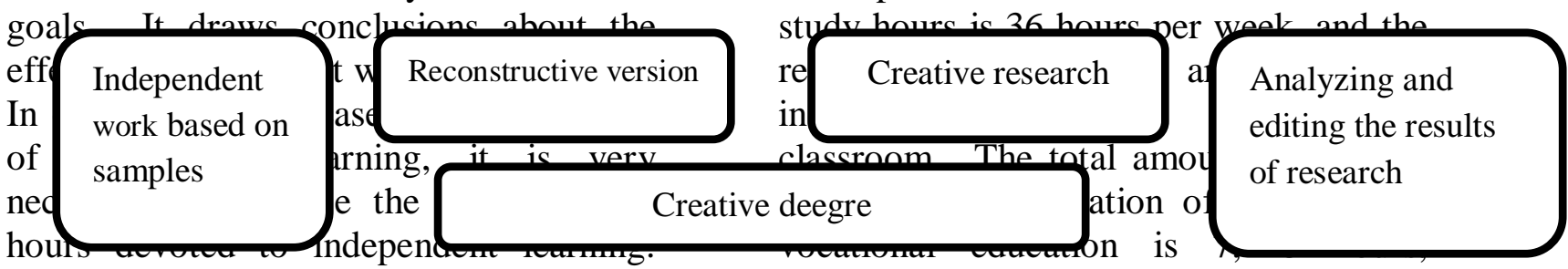

For teachers, in order to direct students to independent work, it is important to improve their skills, and teachers must effectively organize independent learning and prepare students psychologically for including 2,776 hours of independent work hours. This shows that $33.3 \%$ of the load on the curriculum for undergraduate education is focused on independent learning. During independent work, 
students take into account the interdisciplinary approach, select the study literature, write out the necessary information from them, analyze them,

study the content of the independent work and gain insights into this work. This can be seen in Table 1.1.

Table 1.1

Number of hours allocated for the preparation of bachelor teachers in the field of vocational education

(Example 5111000 - Vocational Education (Zootechnics))

\begin{tabular}{|l|l|l|l|}
\hline \multirow{2}{*}{ The name of the science block } & Student work volume (hours) \\
\cline { 2 - 4 } & Total hours & $\begin{array}{l}\text { Auditory } \\
\text { classes }\end{array}$ & $\begin{array}{l}\text { Independent } \\
\text { education }\end{array}$ \\
\hline $\begin{array}{l}\text { Humanities and socio-economic } \\
\text { sciences }\end{array}$ & 1102 & 666 & 436 \\
\hline Mathematical and natural sciences & 1284 & 792 & 492 \\
\hline General professional subjects & 3318 & 2258 & 1060 \\
\hline Specialty subjects & 1070 & 810 & 260 \\
\hline Additional subjects & 354 & 226 & 128 \\
\hline Total & 7128 & 4752 & 2376 \\
\hline
\end{tabular}

A part of the problem is allowed to work independently outside the classroom (library, lab, etc.). When setting up an independent work program, the student will be asked questions and questions that can be used scientifically, practically, and which can be applied creatively to the knowledge they are learning and avoiding duplication.

In the process of independent learning of students, they develop direct research activities. This, in turn, encourages research, and in this process they integrate into a system of interconnected experiences [2].

After the students' independent preparation of the syllabus has been completed, interesting questions are raised in the literature they have read to exchange ideas. Students who are actively involved in the discussion and debate on this topic are assessed by the teacher.

Independent learning activities of students in the field of vocational education accelerate the process of acquiring knowledge and practical activities, the process of selecting technological processes and technical resources, the processes of creative thinking, and form independent and active thinking as a prerequisite for high intellectual development.

Formation of skills and ability to work independently in the preparation of undergraduate teachers in the field of vocational education is regulated by:

- cognitive skills that play an important role in the study of the human being, enriching their life experiences, understanding the means of impact on the environment, and at the same time developing their abilities;

- students acquire the necessary knowledge, skills and abilities in the practical activity, in this process the teacher learns to observe, test their observations by experience, work with the educational literature and use the information in the daily life.

It is advisable to use the methods of vocational education to determine the level of self-education skills of students. They can be conditionally named as:

1. The ability to distinguish between the common and the private (distinguishing skills) in the study of learning materials and the organization of independent work processes.

2. Ability to choose technological processes and technical facilities, to carry out independent work, to draw technical drawings, schemes (ability to create). 
3. Ability to organize independent work in the classroom, outside the classroom, in the classroom and at home.

4. Independent Thinking Skills (Thinking Skills)

5. Self-control skills (control skills) when studying material.
Table 1.2 shows the performance of students' independent skills and abilities. Developed skills of independent work of students in the classroom and off-site, as well as indicators of independent activity of students, the dynamics of their level of development.

Table 1.2

Deegrees of students' independent learning

\begin{tabular}{|c|c|c|}
\hline No. & $\begin{array}{l}\text { Independent Learning } \\
\text { Skills }\end{array}$ & Deegres of Independent learning \\
\hline 1 & $\begin{array}{l}\text { Ability to distinguish } \\
\text { typicality and specificity } \\
\text { from study materials and } \\
\text { organization of independent } \\
\text { work }\end{array}$ & $\begin{array}{l}\text { Effective and quick separation of key features of the } \\
\text { learning material from the main content. Rely on your } \\
\text { own knowledge, skills and teacher support in choosing } \\
\text { technological processes and technical facilities }\end{array}$ \\
\hline 2 & $\begin{array}{l}\text { Ability to choose process, } \\
\text { read, write, draw, } \\
\text { schema, } \\
\text { technological processes and } \\
\text { technical objects during } \\
\text { independent work }\end{array}$ & $\begin{array}{l}\text { Ability to advance technological processes from a } \\
\text { scientific point of view, has a high rate of work on } \\
\text { selecting technical facilities, reading, writing, } \\
\text { performing labor operations, and has the ability to } \\
\text { select and analyze the work process independently. }\end{array}$ \\
\hline 3 & $\begin{array}{l}\text { Ability to effectively } \\
\text { organize independent work } \\
\text { in the classroom, outside the } \\
\text { classroom, and at home }\end{array}$ & $\begin{array}{l}\text { Properly allocates time for technical tasks, properly } \\
\text { utilizes teaching aids, and actively pursues learning } \\
\text { tasks, selects the tools and technological processes to } \\
\text { suit their potential }\end{array}$ \\
\hline 4 & $\begin{array}{l}\text { The ability to think } \\
\text { independently }\end{array}$ & $\begin{array}{l}\text { Knows how to solve technical problems independently } \\
\text { and creatively, introduces independent elements and } \\
\text { methods in practical work, solving problems, } \\
\text { independently choosing elements of creativity and } \\
\text { creativity in practical tasks and exercises, optimal } \\
\text { methods of practical work. }\end{array}$ \\
\hline 5 & $\begin{array}{lll}\text { Self-control skills } & \text { in } \\
\text { material study } & & \end{array}$ & $\begin{array}{l}\text { Examines self-control in the learning process with } \\
\text { additional questions and self-study assignments to } \\
\text { determine the level of self-development, analyzes the } \\
\text { quality of practical work, conducts independent } \\
\text { research on errors, learns new methods as a result of } \\
\text { corrections. }\end{array}$ \\
\hline
\end{tabular}

This table shows what students need to achieve in order to achieve their degree. There are many different ways in which students can be trained to work independently.

1. Students are provided with an example of solving a technical problem, a sample, after which students independently or collectively solve a similar problem. They will be given a technological map of practical work, and students will be able to carry out activities independently based on the map. Based on their experience, students are asked to design a common activity plan, that is, to demonstrate the ways in which they use problem solving and practical exercises.

2. Students are provided with ready instructions (plan or algorithm) for solving the technical problem, stages of 
practical work, examples of their application and assignments for independent work. During the process, the most difficult stages of the assignment are learned in a team.

3. Students will be given a plan to solve a problem or exercise in one of the topics. As they practice it, students move on to a different topic, for which they are asked to create a plan using previous exercises as examples.

4. Students are provided with a general plan of independent work and a method of refinement. They begin by doing a specific topic, drafting an overall plan for the training theme, and then reinforcing it during a technical problem or practical exercise.

5. Students are provided with insights into how to plan a problem-solving process or practical exercises on a given topic, section. The developed plans are then used by students in their own work.

\section{Conclusion}

The attention has been given to the criteria for determining the content, features and qualifications of independent education and the need to develop it, independently expressing the purpose and task of the problem, developing the methodology for independent work and the necessity to identify the main and specific stages of the problem. It also assumes that the problems developed by the methodology and the plans, which are of theoretical and practical nature.

\section{References}

1. Andrianov P.N. The development of technical creativity in labour traning of students of secondary schools: Diss. cand. ped. sciences. - M.: 1985. - 234p.

2. Аскаров, И. Б. (2017). Основные подходы и принципы подготовки будущих педагогов профессионального обучения к исследовательской деятельности. Актуальные научные исследования в современном мире, (2-6), 25-32.

3. Аскаров, И. Б. (2016). Подготовка к исследовательской деятельности будущего педагога профессионального обучения. мастерство (pp. 39-42).

4. Demidova S. I., Denischeva L.O. Independent activities of students in teaching mathematics. - M.:Education, $1985-189$ p.

5. Matchanov S. Organization of literature-independent work in the general education system: Autoref. dis. ... Ped. T.: 1998. - 42 b.

6. Muslimov N.A. Professional formation of future vocational education teachers. Monograph. - $\mathrm{T}$.: Science, 2004. - $128 \mathrm{p}$.

7. Muslimov NA, Kuysinov OA Organization of independent education in the preparation of vocational training teachers. Methodical manual. - T . TSPU, 2006. - 46 p.

8. Nishonova Z. Psychological criteria for the development of independent thinking // Public education. - Tashkent, 2001.- No. 1- B. 38 - 40.

9. Tolipova J. Organization of independent students' education // Public education. - Tashkent, 2002. - No. 4. - B. $102-103$.

10. Khalilov N. Independent forms of education // Public education. - Tashkent, 2002.- No. 5.- B. 88 - 89.

11. Husanboeva Q.P. Scientific and methodological foundations for teaching students to think independently in literary education: Dis. ... Ped. -Tashkent: UzPFITI, 2004. - 261 p.

12. Husainov R.R. The role of independent learning in improving the quality of teaching science in higher education // Modern education. - 2016. No. 4. 25-32 p.

13. Usmanov S. A. Features Implementing European Credit and Modular System at Higher Education Institutions of Uzbekistan //Eastern European Scientific Journal. - 2019. - №. 
1.

14. Sharipov Sh. S. Pedagogical conditions of the formation of students' creativity. (On the example of Labor and Vocational Education Faculty): Dis.

ped. science. name - T .: 2000. - 205 p.

15. Yunusova Sh. Formation of independent learning activity of students // Public education. - Tashkent, 1997. - №5.

- B. 53 - 55. 